\title{
A!
}

This is an electronic reprint of the original article.

This reprint may differ from the original in pagination and typographic detail.

Shakil, Saani; Lu, Wei; Puttonen, Jari

\section{Response of high-strength steel beam and single-storey frame in fire : Numerical simulation}

Published in:

Journal of Constructional Steel Research

DOI:

10.1016/j.jcsr.2018.06.010

Published: 01/09/2018

Document Version

Peer reviewed version

Published under the following license:

CC BY-NC-ND

Please cite the original version:

Shakil, S., Lu, W., \& Puttonen, J. (2018). Response of high-strength steel beam and single-storey frame in fire : Numerical simulation. Journal of Constructional Steel Research, 148, 551-561.

https://doi.org/10.1016/j.jcsr.2018.06.010

This material is protected by copyright and other intellectual property rights, and duplication or sale of all or part of any of the repository collections is not permitted, except that material may be duplicated by you for your research use or educational purposes in electronic or print form. You must obtain permission for any other use. Electronic or print copies may not be offered, whether for sale or otherwise to anyone who is not an authorised user. 


\title{
Response of high-strength steel beam and single-storey frame in fire: numerical simulation
}

\author{
Saani Shakil*, Wei Lu, Jari Puttonen \\ Aalto University, Department of Civil Engineering, Finland
}

\begin{abstract}
$\underline{\text { Abstract }}$
The design principles for high strength steel (HSS) structures exposed to fire are under development. In this paper, the response of HSS structures in fire is studied through numerical simulation of a beam and a two-bay frame. Geometrical imperfections and residual stresses are introduced into the structural models. Deformation limit criteria are used to compare the critical temperatures of the structures made of HSS and mild steel. The comparisons show that HSS structures have higher strength reserve than mild steel structures. Using the mechanical properties at elevated temperatures from literature sources, it is observed that the deflection behaviour of the studied structures depends on the ratio of strength to elastic modulus. The deflection of the studied beam is sensitive to yield strength reduction factors as the beam fails by plastic hinge mechanism. Whereas, the deflection of the HSS frame is sensitive to the reduction factors of the elastic modulus as the frame fails by inelastic instability. The above-mentioned observations on the studied structures are made using a threestage mechanism which is developed for interpreting the deformation response.
\end{abstract}

Keywords: High strength steel; mechanical properties at elevated temperature; beam and frame structures in fire; performance-based fire design

\section{Introduction}

High strength steel (HSS) has gained popularity in recent years due to its possible applications in the construction industry. Its high strength-to-weight ratio encourages in designing structures with long spans or reduced cross-sections. The comparatively light structure of HSS leads to savings in transportation costs. Slim structures are less obstructive and aesthetically pleasing as well. Despite the obvious advantages, there are certain hurdles regarding structural fire safety design using HSS. The long span structures leading to open space design change the fire exposure. For the available HSS, the elastic modulus is nearly the same as mild steel while the yield strength is twice or more, therefore there is a limitation on the serviceability limit state design. These issues require revision and renewing of the current structural fire safety design (FSD) method. Performance-based FSD takes into account different fire scenarios and complex structural material properties in order to study the structural performance close to reality ( [1], [2], [3] ). The present work particularly focusses on the effect of HSS material properties on the response of structures.

The degradation of mechanical properties of carbon steel at elevated temperature is presented in EN 1993-1-2 [4]. The applicability of the temperature dependent reduction factors has been extended from S460 to S700 grade steel in EN $1993-$ 1-12 [5]. Since the reduction factors in EN 1993-1-2 are provided through research and tests on mild steel (below S460), the advantage offered by the increased strength of HSS is not fully reflected in these reduction factors. Therefore, material tests to obtain the mechanical properties of HSS have been carried out in recent years ( [6], [7], [8], [9], [10], [11], [12], [13]). Transient and steady state tensile tests were carried out for determining the mechanical properties of S700QL (quenched and low temperature toughened) at elevated temperatures in 2014 by Outinen et al. [6]. The heating rate of $20^{\circ} \mathrm{C} / \mathrm{min}$ was used for both testing methods. The stress levels used for S700 in transient tests were 30, 45, 60, 80, 120, $170,230,280,350,420,490,560,630$, and $700 \mathrm{~N} / \mathrm{mm}^{2}$. The temperature levels used for S700 in steady state tests were $20,500,600$, and $700^{\circ} \mathrm{C}$. Yield strength values from tests are taken corresponding to 0.2 and $2 \%$ strain offset. Due to limited number of test specimens, the elastic modulus was not measured. The steel used in the tests fulfilled the criteria of the delivery conditions for quenched and tempered steel according to EN 10025-6 [14].The reduction factors of effective yield strength at $2 \%$ strain offset obtained from transient and steady-state tests are shown in Figure 1. 


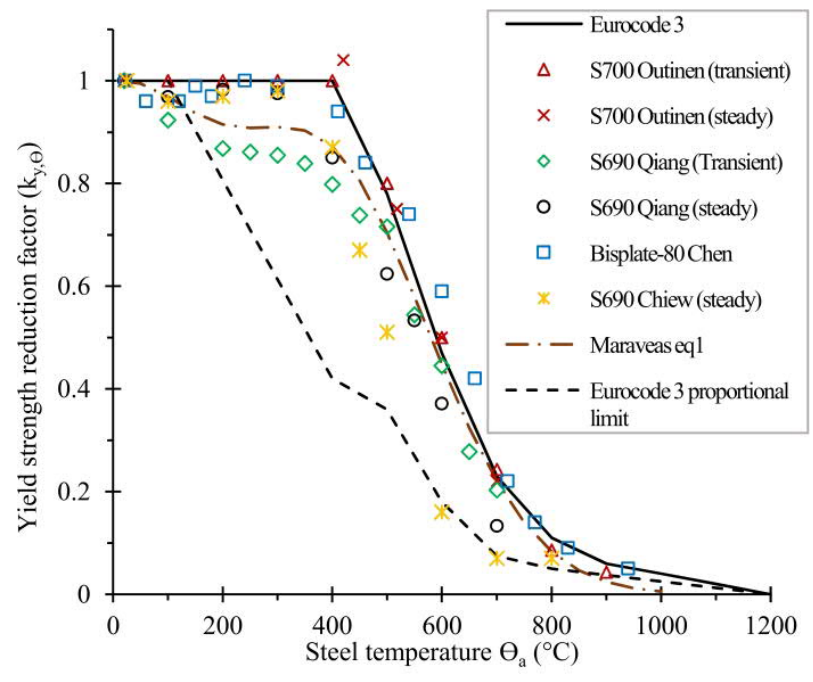

(a)

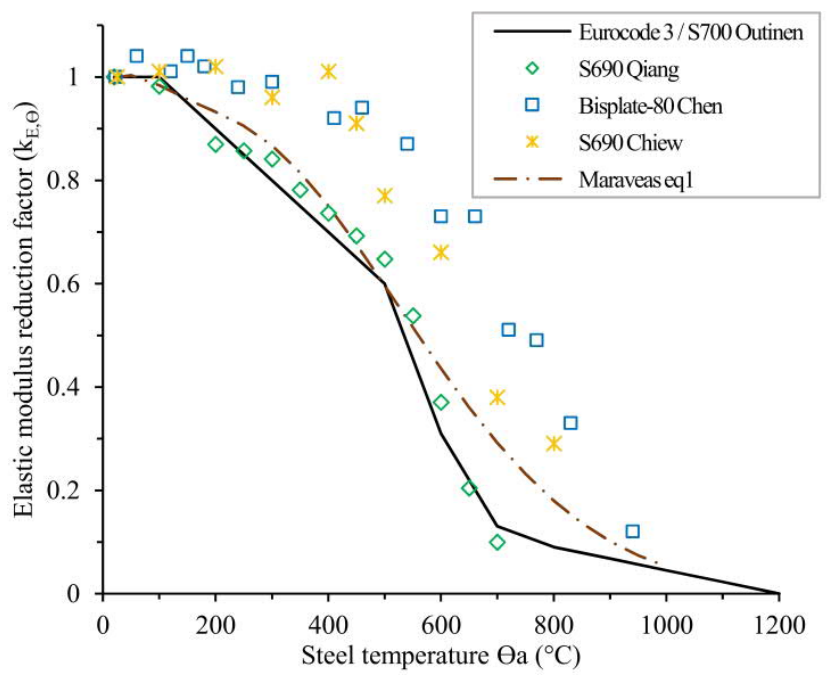

(b)

Figure 1 Comparisons of temperature dependent mechanical properties from literature to EN 1993-1-2 (a) Reduction factors for yield strength (b) reduction factors for modulus of elasticity

Mechanical properties of steel grades close to nominal yield strength of $700 \mathrm{~N} / \mathrm{mm}^{2}$ at elevated temperatures from different research groups (Outinen et al. [6], Qiang et al. [11], Chen et al. [10], and Chiew et al. [12]) are selected for the current study. Maraveas et al. [15] proposed two equations for the reduction factors which takes into account the available material properties of steels having average yield strength ranging from $510 \mathrm{~N} / \mathrm{mm}^{2}$ to $1300 \mathrm{~N} / \mathrm{mm}^{2}$. One of the proposed equations has been selected for the current study. The reduction factors of yield strength and modulus of elasticity from some of the above-mentioned literature are compared with those from EN 1993-1-2 in Figure 1 (a) and (b), respectively. The yield strength reduction factors are taken at $2 \%$ strain offset values for all literatures. Chen et al. [10] did not provide clear information about the test method used for the reduction factors provided by them. Proportional limit reduction factors are also provided by EN 1993-1-2 (Figure 1), but there is little data available in the literature sources.

The reduction factors of HSS obtained through tensile tests at elevated temperature from above mentioned literature show considerable variations when compared to EN 1993-1-2 reduction factors (Figure 1). The comparisons show that the results from Outinen et al. [6] (hereafter as Outinen-model) are very close to EN 1993-1-2 values for both yield strength and modulus of elasticity. The yield strength values provided by Qiang et al. [11] (hereafter as Qiang-model) are lower, and the values of modulus of elasticity are close to EN 1993-1-2 values. On the other hand, the values of yield strength provided by Chen [10] (hereafter as Chen-model) are close to those of EN 1993-1-2 but modulus of elasticity values are considerably higher. For the results from Chiew's tests [12] (hereafter as Chiew-model), the yield strength values are lower, while the values of modulus of elasticity are considerably higher than EN 1993-1-2 values. The yield strength is close to the proportional limit after $600^{\circ} \mathrm{C}$. Maraveas et al. [15] (hereafter as Maraveas eq1) has values which lie roughly at the middle of the scatter of the reduction factors of the literature sources. Li [16] has measured the modulus of elasticity of several high strength steels at elevated temperatures using both static and dynamic methods and the results show that the reduction factors provided by current EN 1993-1-2 are overly conservative. Therefore, EN 1993-1-2 provided material properties of HSS at elevated temperature could be further revised taking into account the observed variations from recent tests.

Using the available mechanical properties of HSS at elevated temperature, studies on structural behaviour have been carried out. Varol and Cashell [17] studied the buckling response of S690 grade steel beam at high temperatures using EN 19931-2 reduction factors and concluded that buckling curves provided in EN 1993-1-2 are not always safe. HSS connection behaviour [18] and column behaviour [19] [20] at elevated temperature was also studied recently. Elevated temperature behaviour of HSS frames was studied by Shakil et al. [21] in which recent material data from literature was used for material modelling. The studies highlighted the deviations of mechanical properties observed in recent HSS material tests and concluded that the use of reduction factors provided in EN 1993-1-2 for material modelling for HSS frames may lead to underestimation of critical temperatures. Further confirmation studies are therefore necessary, especially dealing with the effect of variations of measured mechanical properties on the deformation behaviour of HSS structures.

In the present study, a 3D finite element (FE) model considering both material and geometrical non-linearity is created firstly for a beam structure with available test results. For the material modelling, stress-strain curves formulation given in EN 1993-1-2 is selected, and then the temperature dependency is introduced with the help of reduction factors. An explicit 
FE analysis procedure is selected based on the non-linear nature of the problem. The FE modelling is validated against the test values of the selected mild steel beam structure from literature. The possibilities of extending the validated FE modelling of mild steel beam to HSS beam is then studied. After that, the sensitivity of the response for the scattering of the mechanical properties of HSS observed in literature on the behaviour of beams are investigated. Furthermore, similar studies are then extended to the steel frame structure. The study highlights the suitability of the reduction factors provided by EN 1993-1-2 for HSS structural applications. Both geometrical imperfections and residual stresses are considered in creating FE models to study the behaviour of beam and frame structures. The benchmark tests to validate FE models have been performed on steel beams and steel frames, and the studies of this paper focus on the effects of scattering of mechanical properties on the structural response. Therefore, the temperature gradient inside the steel beam due to floor effects has not been taken into account.

\section{FE modelling for analysis}

Abaqus software version 6.13-3 [22] and its explicit procedure has been selected for numerical simulation. The explicit procedure is preferred in order to avoid convergence issues with non-linear problems with large deformation. Quasi-static events can be simulated using the explicit dynamic solver, which is computationally efficient compared to implicit solvers.

\subsection{Structure and meshing}

Rubert and Schaumann [23] have performed elevated temperature tests for the beam structure with normal rolled sections. Extensive details of these tests have been provided by the authors in their paper and the results have been widely used by other researchers for validation studies [24] [25] [26] [27]. The setup of the beam test and the dimensions of the beam profile (IPE 80) is shown in Figure 2. The measured yield strength of $399 \mathrm{~N} / \mathrm{mm}^{2}$, i.e. $\sigma_{\mathrm{y}}=399 \mathrm{~N} / \mathrm{mm}^{2}$, is provided for the steel beam. In these tests, mechanical load (F) is applied at the center of the beam and is kept constant throughout the experiment. The temperature of the beam is increased uniformly until the beam deforms up to a certain limit. Three different heating rates are used in the tests, and they are intended to simulate the heating of the beam with or without fire protection. In the present study, the FE modelling of the same beam structure as in [23] is developed and is then used as an analysis tool to study the behaviour of HSS beams.

The element type selected is C3D8R which is a 3D continuum 8-node brick and uses reduced integration. In order to avoid hourglassing complication caused by the linear element type, the beam cross-section is discretized with four elements across the thickness of the flange and the web (Figure 2 (a)). Based on the mesh sensitivity analysis, the rest of the crosssection and the beam length is evenly meshed (Figure 2 (b)) to keep the element size reasonable for computational efficiency and output accuracy.

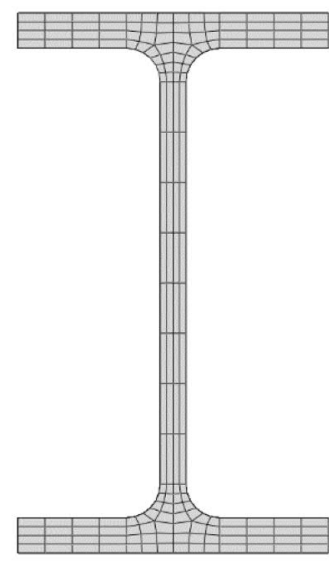

(a)

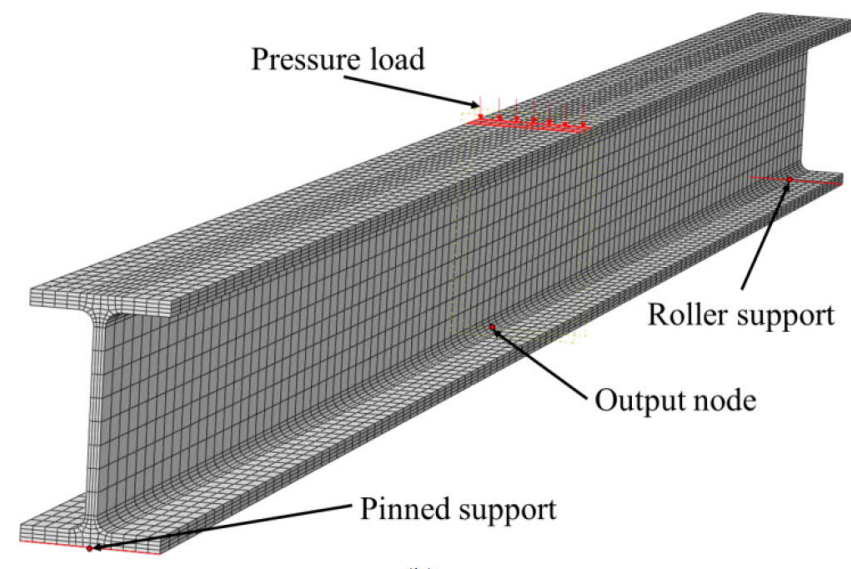

(b)

Figure 2 FE model of IPE-80 beam (a) mesh discretization of cross-section and (b) load, boundary conditions, and node for displacement output (span of the beam is $1140 \mathrm{~mm}$ )

\subsection{Material modelling}

For the finite element simulation, material modelling is required to describe the behaviour of the steel at various stages of mechanical and thermal loads. Equations for carbon steel provided in EN 1993-1-2 [4] are used to define stress-strain curves at elevated temperatures. To take into account the change of material properties with respect to temperature, reduction factors of yield strength, elastic modulus and proportional limit are integrated into these equations. Engineering stress-strain curves at different temperatures are thus obtained. These curves can then be converted into true stress vs. true plastic strain curves (presented in [21]) which are used for non-linear material data input in FE analysis. Similarly, reduction factors from literature are used to obtain their respective material model for FE simulation input for parametric studies in 
later sections. For all the cases, the Poisson's ratio is taken as 0.3 , and the thermal expansion behaviour of carbon steel is adopted from EN 1993-1-2 [4].

\subsection{Modelling of geometrical imperfections and residual stresses}

Similar to the studies on the behaviour of steel members at room temperature, both geometrical imperfections and residual stresses are taken into account when FE model is created for the beam in fire. In this paper, the geometrical imperfection according to section 5.3.4 of EN 1993-1-1 [28] has been adopted in order to study its effect on the behaviour of both the beam and the frame. The amplitude of imperfection is taken as $k * e_{0, d}$, where $e_{0, d}$ is the design value of maximum amplitude of imperfection (taken as $L / 250$ ) at the mid-span and about the weak axis of the profile. The recommended value of $\mathrm{k}$ according to Eurocode is 0.5 , and the same is adopted for the analysis. The geometric imperfection mode is generated by buckling analysis in Abaqus. The mode shape and amplitude of imperfection is introduced in the stress analysis step through nodal displacements.

For the purpose of assigning the residual stresses to the profile, the beam is partitioned into 28 parts as shown in Figure 3 (a). Because of the symmetry of the profile, only 9 parts are numbered. Two methods have been used when assigning the residual stress to the portioned parts. One is to assign the full amplitude (simplified distribution) of the corresponding compressive and tensile residual stresses to the partitioned parts as shown with red dotted lines in Figure 3 (a). The other is to assign the average of the stress distribution (typical distribution) to each portioned part which is more commonly used for hot rolled I-section profiles. For typical distribution of residual stress, the average values of stress corresponding to each part are shown in Figure 3 (b). For partition number 1, owing to its complex shape the residual stress corresponding to its centroid is taken for analysis input.

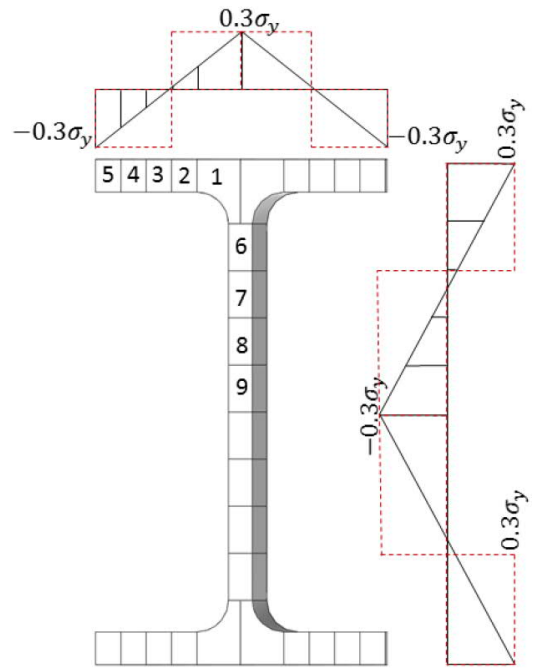

(a)

\begin{tabular}{|c|c|}
\hline $\begin{array}{c}\text { Partition } \\
\text { number }\end{array}$ & Residual stress assigned \\
\hline 1 & $0.77 *\left(0.3 \sigma_{y}\right)$ \\
\hline 2 & $0.22 *\left(0.3 \sigma_{y}\right)$ \\
\hline 3 & $-0.14 *\left(0.3 \sigma_{y}\right)$ \\
\hline 4 & $-0.47 *\left(0.3 \sigma_{y}\right)$ \\
\hline 5 & $-0.82 *\left(0.3 \sigma_{y}\right)$ \\
\hline 6 & $0.3 *\left(0.3 \sigma_{y}\right)$ \\
\hline 7 & $-0.068 *\left(0.3 \sigma_{y}\right)$ \\
\hline 8 & $-0.44 *\left(0.3 \sigma_{y}\right)$ \\
\hline 9 & $-0.81 *\left(0.3 \sigma_{y}\right)$ \\
\hline
\end{tabular}

(b)

Figure 3 Assigning residual stress to the profile (a) residual stress distribution across the profile (typical distribution in solid lines and simplified distribution in dotted lines) (b) average values of stress for each portioned parts (oy is the yield strength of the steel)

\subsection{FE analysis implementation}

Mechanical load is applied as a pressure load at the middle of the top flange of the beam as shown in Figure 2 (b). The mechanical load once applied is set to remain constant throughout the simulation. Thermal load is applied as a pre-defined temperature field about the whole beam. The thermal load is set to increase uniformly with the step time to simulate the heating of the beam as performed in the tests. The upper limit of temperature attained at the end of step time is set to cover the maximum expected critical temperature of the beam. The FE simulation is divided into the following three steps:

1. Initial step: Simply supported boundary conditions are applied to the beam. Initial temperature of the beam is assigned.

2. Load step 1 (time period of 5s): Mechanical load is applied at the center of the beam using smooth step amplitude. The initial temperature of the beam is maintained.

3. Load step 2 (time period of 30s): Mechanical load is kept constant while uniformly increasing temperature load is applied so that it reaches $1000^{\circ} \mathrm{C}$ at the end of this step. 
The simple supports are provided at the lower flange of the beam similar to the tests as shown in Figure 2 (b). The deformation output is taken from the node located at the middle of the bottom flange of the beam as shown in the same Figure 2 (b).

\section{FE model validation and failure mechanism}

In order to obtain economical quasi-static solutions with an explicit dynamic solver, two transformation approaches are used: artificially reducing the actual time period of the test to the time scale of the simulation; and artificially increasing the material density to increase the stable time increment (mass scaling). The simulation time period is taken to be considerably longer than the time period of the beam based on its first natural frequency. Effect of using different mass scaling values on the computational efficiency and the accuracy of the output is studied. Based on the studied results, a mass scaling factor value of 1000 is selected for the present simulation. The dynamic effects become significant due to artificially reducing the time period of simulation and introducing mass scaling. Therefore, both kinetic and internal energy are monitored throughout the simulation. With a reasonable accuracy, the response can be considered to be in quasi-static state if the kinetic energy of the system remains below $10 \%$ of internal energy [22]. After fixing these parameters, the finite element model is validated by the beam tests conducted by Rubert and Schaumann [23]. This validated model is then used for parametric studies.

\subsection{Validation of FE modelling}

The mid-span deformation with respect to temperature from FE analyses is compared with experimental tests in order to validate the FE modelling. The comparison results for the four cases of load utilisation ratios are shown in Figure 4 (a). Load utilisation ratio is defined as the ratio of the load applied to the cross-sectional load bearing capacity of the beam. When the load utilisation ratio is 0.2 , the results from $\mathrm{FE}$ analysis are close to the results from tests with heating rate of 5.3 ${ }^{\circ} \mathrm{C} / \mathrm{min}$. For other load utilisation ratios, the test results with heating rate of $2.67{ }^{\circ} \mathrm{C} / \mathrm{min}$ are presented for comparison with $\mathrm{FE}$ analysis results. It can be seen that the simulation values of the mid-span deformation of the beam with respect to temperature agree well with the test values. Hence, the developed FE modelling can further be used for studying similar problems with acceptable level of accuracy.

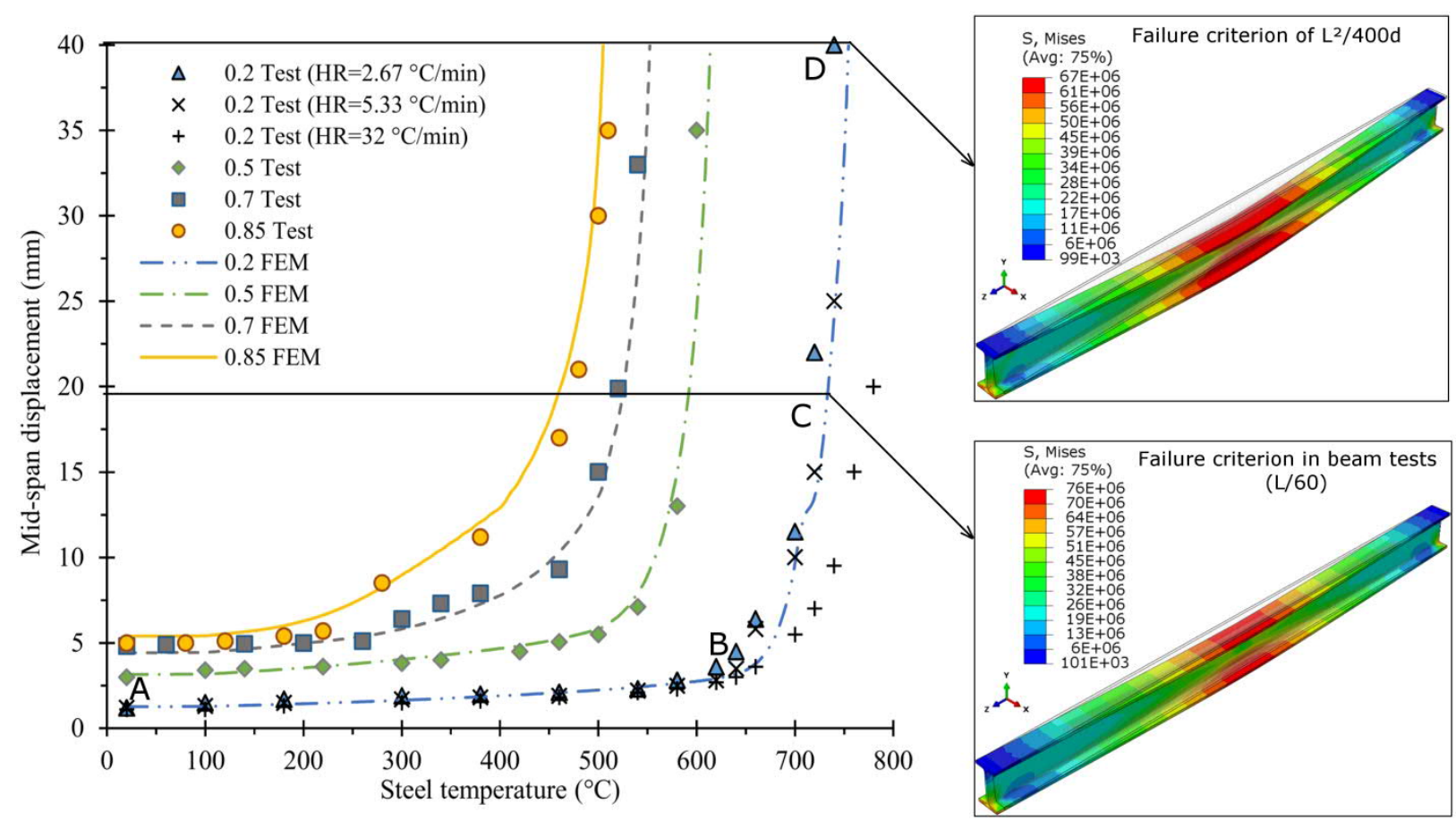

(a)

(b)

Figure 4 Validation of FE model against results from tests (a) Mid-span displacement vs temperature at different load ratios (b) Deformation mode and stress (units $=\mathrm{Pa}$ ) contours at critical temperature defined according to the corresponding failure criterion from FE analysis

\subsection{Critical temperature for the beam member}

Critical temperature is defined as the temperature when the load resistance of the beam is less than the load applied to it. In fire, an increase in stress to a value higher than the effective yield stress may not cause the immediate collapse of the 
structure but often initiates a visibly ductile phase of deformations. As a simplification, Rubert and Schaumann [23] has set the failure criterion of the beams as the mid-span deformation of $L / 60$ ( $L$ is the span length). According to Rubert and Schaumann [23], the limit of $\mathrm{L} / 60$ is close to the limitation of deformation rate defined as

$\frac{d D}{d t}=\frac{L^{2}}{9000 d} \mathrm{~mm} / \mathrm{min}$

where $L(\mathrm{~mm})$ is the clear span of the specimen, and $d(\mathrm{~mm})$ is the distance between the extreme fibre of compression and tension zone of the structural section at room temperature. In the current European standard EN 1363-1 [29], equation (1) is provided as one of the criteria to define the load-bearing failure for flexural members. Besides this equation, EN 13631 also gives the deflection limit criterion as:

$D=L^{2} / 400 d \mathrm{~mm}$

When the deflection limit criteria are used, the studied beam is considered to fail at $19 \mathrm{~mm}$ mid-span deformation corresponding to $L / 60$ criterion, and at $40 \mathrm{~mm}$ mid-span deformation corresponding to EN 1363-1 criterion. With load ratio of 0.2 and heating rate of $5.33^{\circ} \mathrm{C} / \mathrm{min}$ the critical temperatures of the beam for the tests are $730{ }^{\circ} \mathrm{C}$ and $750{ }^{\circ} \mathrm{C}$ using $L / 60$ and EN 1363-1 criterion, respectively. As can be seen in Figure 4 (a), the critical temperatures from $\mathrm{FE}$ analysis corresponding to these two criteria are $732{ }^{\circ} \mathrm{C}$ and $752^{\circ} \mathrm{C}$, respectively, which are close to the critical temperature values from tests. Figure 4 (b) shows deformation modes and stress contours corresponding to these two criteria. The yield strength of steel is reduced to $50 \mathrm{MPa}$ at around $730^{\circ} \mathrm{C}$. It can be seen that a clear plastic hinge is formed in the middle section of the beam when the mid-span displacement is $40 \mathrm{~mm}$, whereas a plastic hinge is about to form when the deflection is 19 $\mathrm{mm}$. Because of the close critical temperatures reached and clear plastic hinge mechanism, the deflection limit defined in EN 1363-1 is selected for further simulations.

3.3 Failure mechanism for the beam member

With the help of deformation - temperature curves corresponding to load ratio of 0.2 in Figure 4 (a), the deformation history of the studied beam in fire can be divided into the following three stages:

1. Stage AB: In this stage, the beam deformation increases slightly with the increase of temperature. Beam behaves linearly up to the temperature at which the maximum stress of the beam due to the applied load equals to the proportional limit corresponding to this temperature. This temperature is denoted as $\theta_{\text {elastic }}$ and is useful to identify the reserve strength of the structure once it enters the non-linear deformation stage. The temperaturedependent proportional limit is defined as the yield strength multiplied by the reduction factor for proportional limit. Therefore, the temperature of $\theta_{\text {elastic }}$ is determined by the load ratio. With the given load and beam profile, the deformation of the beam depends on the reduced modulus of elasticity, i.e. $E_{\theta}$.

For simplicity and uniformity, limiting angle ( $\left.\alpha_{\text {elastic }}\right)$ to determine point B (lying in the vicinity of the observed proportional limit exceedance) is proposed. $\alpha_{\text {elastic }}$ is the angle formed by the line segment $\mathrm{AB}$ and a horizontal line starting from point A. Since the L/60 and EN 1363-1 deformation limit criteria are deflection based, this limiting angle criterion helps to mark the start of proportional limit based on deflection as well. This limiting angle $\left(\alpha_{\text {elastic }}\right)$ is set at $0.2^{\circ}$ for all the cases of load ratios. This angle approach is case dependent as it has not been tested with an exhaustive number of structural cases.

2. Stage BC: In this stage, the beam deforms rapidly with small increment of temperature. The non-linear deformation behaviour is marked by the large deformation rate with respect to temperature. This non-linear behaviour is a result of material non-linearity. The modulus of elasticity reduced with temperature changes to tangent modulus reduced with temperature. The Stage BC ends at the temperature when the temperaturedependent tangent modulus is reduced to nearly zero, i.e. the strain in the profile reaches the yield strain of 0.02 as defined in EN 1993-1-2. Figure 4 (b) shows that the material begins to yield near the mid-span at deformation limit of $\mathrm{L} / 60$. Therefore, the end of Stage $\mathrm{BC}$ can be defined when the beam deformation reaches this deformation limit. The corresponding temperature at this deformation limit is expressed as $\theta_{L / 60}$. With the given applied load and beam profile, the deformation of the beam at this stage depends on the tangent modulus which is varied with temperature, i.e. $E_{t . \theta}$.

3. Stage CD: In this stage, the beam enters the runaway deformation phase. In this range, the plastic zone spreads across and along the beam from the cross-section with maximum developed stress. Progressively, more material points develop zero tangent modulus and the spreading of the plastic zone depends on the shape factor of the profile. As a full plastic hinge is developed at the section, the plastic rotation occurs. The deformation allowed, is 
limited by the deformation limit given in EN 1363-1. Figure 4 (b) shows the spreading of the plastic zone at this limit. The temperature corresponding to this limit is represented as $\theta_{E N 1363-1}$. The deformation of the beam in this stage depends on both the plastic moment and elastic part available inside the beam at corresponding temperatures. Therefore, the beam deformation in this stage is a function of $f_{y \cdot \theta / E_{\theta}}$, where $f_{y . \theta}$ and $E_{\theta}$ are the yield strength and modulus of elasticity at corresponding temperatures, respectively.

The deformation - temperature curves with other load ratios in Figure 4 (a) show that the beam behaviour is similar to that with the load ratio of 0.2. Due to larger loads, the maximum stresses inside the beam exceed the corresponding proportional limits at lower temperatures and the beam exhibits non-linear deformation much earlier. Therefore, the load ratio decides the duration of Stage AB. The maximum temperatures reached at each stage at various load ratios using FE analysis are listed in Table 1.

\begin{tabular}{|c|c|c|c|c|c|c|c|c|}
\hline Load ratio & \multicolumn{2}{|r|}{0.2} & \multicolumn{2}{|r|}{0.5} & \multicolumn{2}{|c|}{0.7} & \multicolumn{2}{|c|}{0.85} \\
\hline Temperatures & $\mathrm{FE}\left[{ }^{\circ} \mathrm{C}\right]$ & 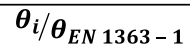 & $F E\left[{ }^{\circ} \mathrm{C}\right]$ & $\theta_{i} / \theta_{E N 1363-1}$ & $\mathrm{FE}\left[{ }^{\circ} \mathrm{C}\right]$ & 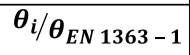 & $F E\left[{ }^{\circ} \mathrm{C}\right]$ & $\theta_{i} / \theta_{E N 1363-1}$ \\
\hline $\boldsymbol{\theta}_{\text {elastic }}$ & 654 & 0.87 & 343 & 0.56 & 229 & 0.42 & 177 & 0.35 \\
\hline$\theta_{L / 60}$ & 732 & 0.97 & 592 & 0.96 & 526 & 0.95 & 458 & 0.90 \\
\hline$\theta_{E N 1363-1}$ & 755 & 1.00 & 614 & 1.00 & 552 & 1.00 & 507 & 1.00 \\
\hline
\end{tabular}

It can be seen from Table 1 that temperatures of $\theta_{L / 60}$ and $\theta_{E N 1363-1}$ are close to each other at load levels of $0.2,0.5$, and 0.7 , respectively, but differ to $10 \%$ at load ratio of 0.85 . Table 1 also shows that temperatures of $\theta_{\text {elastic }}$ under which the beam deform elastically are lower than the critical temperatures of $\theta_{E N} 1363-1$ by $13 \%$ to $65 \%$ when the load ratio is increased from 0.2 to 0.85 , respectively. Because of this difference between $\theta_{\text {elastic }}$ and $\theta_{E N 1363-1}$, EN 1363-1 criterion is more suitable for defining the critical temperature especially when load ratio is 0.85 . Therefore, this failure criterion is selected for further analyses. Based on this criterion, it can be seen from Table 1 that when the load ratio is varied from 0.2 to 0.85 , the critical temperatures decrease from $755^{\circ} \mathrm{C}$ to $507{ }^{\circ} \mathrm{C}$. The load ratio of 0.5 (being commonly used in practice) and 0.85 (as an extreme practical case) are selected for further parametric studies.

\subsection{Effects of geometrical imperfections and residual stresses on the determination of critical temperature}

Figure 5 shows the variations in the mid-span deformation of the studied beam as a function of temperature when geometrical imperfections and/or residual stresses are considered with a load ratio of 0.85 . It can be seen that the maximum difference of deformations between the beams with various combinations of geometrical imperfections and residual stresses is observed at temperature of $250^{\circ} \mathrm{C}$. The difference of $3.8 \%$ in deflection is between the perfect beam and the beam with both geometrical imperfections and residual stress; and the difference of $10.5 \%$ in deflection is between the perfect beam and the beam with both geometrical imperfection and simplified residual stresses. These differences become almost negligible after $425^{\circ} \mathrm{C}$. The differences between critical temperatures are negligible when the deformation limit of $40 \mathrm{~mm}$ is reached for all the studied cases. As shown in Figure 6, all the beams fail with plastic hinge formation at the mid-span, which is the location of the applied load. No lateral-torsional buckling failure has been observed. It can be concluded that the imperfections affect the deformation behaviour in the non-linear phase but have negligible effects on the critical temperatures of the beam when the failure occurs due to the plastic hinge formation. Therefore, the imperfections can be neglect in creating FE model for the beam that has the similar failure mechanism. 

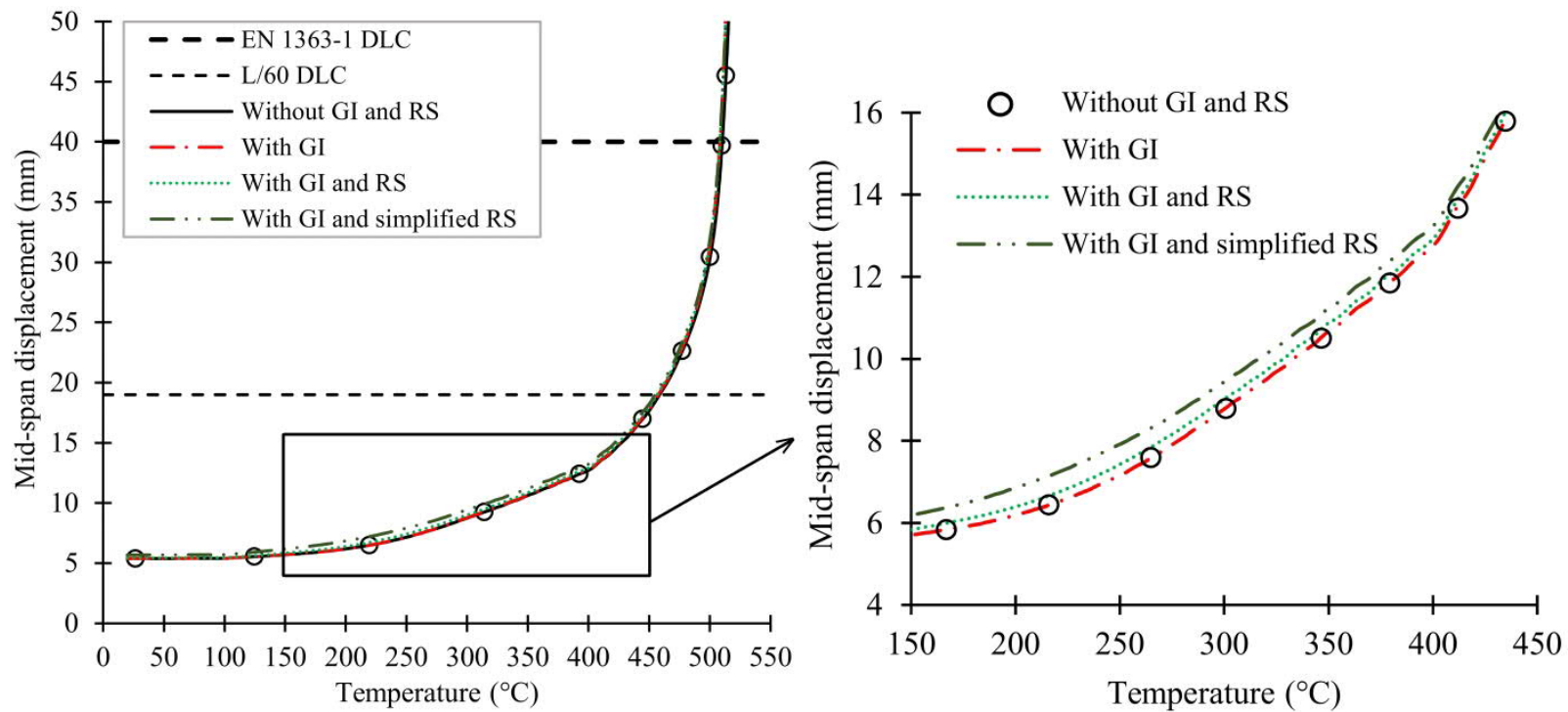

Figure 5 Deformation behaviour of the beam with different combination of imperfection and residual stresses using 0.85 load ratio and EN 1993-1-2 reduction factors for $\sigma_{y}=399 \mathrm{~N} / \mathrm{mm}^{2}$. (GI: geometrical imperfection, RS: residual stress, DLC: deflection limit criterion)

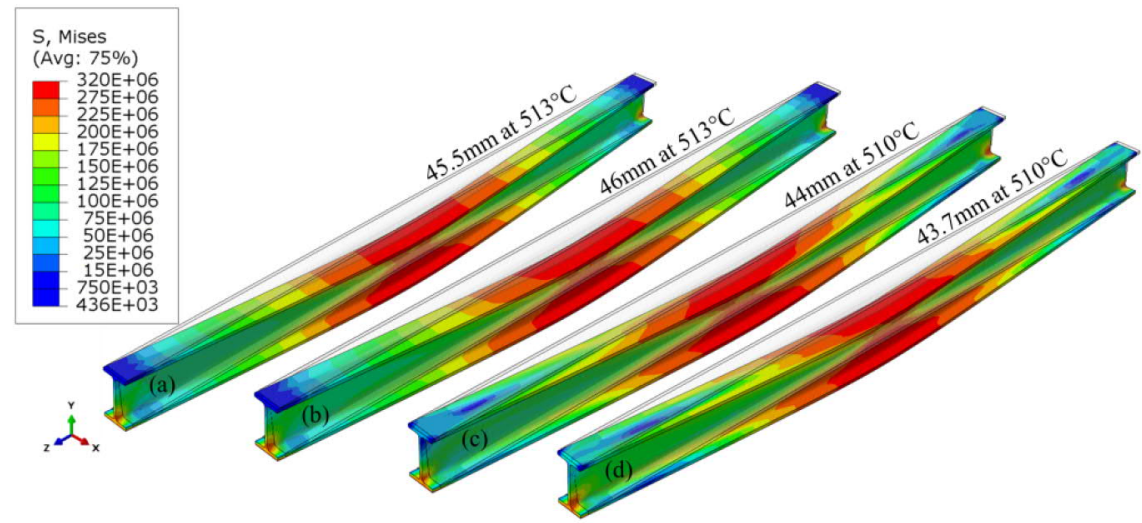

Figure 6 Stress (units $=P a)$ contours of the mild steel $\left(\sigma_{y}=399 \mathrm{~N} / \mathrm{mm}^{2}\right)$ beam after achieving $40 \mathrm{~mm}$ mid-span deformation $(E N$ 1363-1 deformation limit criterion) (a) Without imperfection and residual stress (b) With geometrical imperfection only (c) With both geometrical imperfection and residual stress (d) With both geometrical imperfection and simplified residual stress

\section{Behaviour of high strength steel beam at elevated temperatures}

\subsection{Comparison of the behaviour of HSS beam with mild steel beam}

The material model for high strength steel (HSS) of S700 is used to compare the deformation behaviour of HSS beam with that of mild steel (yield strength, $\sigma_{y}=399 \mathrm{~N} / \mathrm{mm}^{2}$ ). The material models for both steel grades are created based on EN 1993-1-2. Two loading cases are considered for HSS beam for its comparison with the mild strength beam: the same pressure load of $3 \times 10^{4} \mathrm{kN} / \mathrm{m}^{2}$ corresponding to load utilisation ratio of 0.85 for mild steel; and the pressure load with the utilisation ratio of 0.85 to its own resistance. These comparison results are shown in Figure 7 (a) and (b), respectively. Figure 7 (a) shows that the deformation - temperature curves of S700 beam has the same trend as that of mild steel beam but the critical temperature is $100{ }^{\circ} \mathrm{C}$ higher. The increase of the critical temperature comes from the relative longer stage $\mathrm{AB}$ because of the lower load ratio. Figure 8 shows the comparison of the deformation mode of HSS beam with that of mild steel beam at their respective critical temperatures. Plastic hinges in cross-sections at mid-span are observed for both mild-steel and HSS beams. The observed out-of-plane deformation has similar amplitude as of initial imperfection in both cases. No instability failure has been observed. Therefore, both geometrical imperfection and residual stresses have negligible effect on the deformation behaviour of beams of both grades in this case as shown in Figure 7 (a). With similar deformation - temperature curve and similar deformation mode, it can be concluded that the FE models developed based on mild steel beam can be used for further parametric studies for HSS beams.

Figure 7 (b) shows that the deflection for the beam of S700 is greater than that of mild steel up to runaway failure. This is because the same load ratio creates larger load to HSS beam than to mild steel beam. The same profile and the same reduction factor for modulus of elasticity leads to greater deformation of the beam with larger load. Because of the same 
load ratio, the two beams exit from the elastic stage at around the same time despite having different initial deflections. HSS beam has shorter inelastic stage than that of mild steel beam due to smaller temperature-dependent tangent modulus of HSS material, and the plastic rotation of HSS beam is larger as well. The critical temperature for runaway failure of HSS beam is lower than that of mild steel beam by $26^{\circ} \mathrm{C}$.

The results shown in Figure 7 (a) and (b) indicate that the use of HSS can increase the load bearing capacity of the steel beam at elevated temperature. However, when the strength increases and the elastic modulus remains the same (for HSS case), higher load ratio can enlarge the deformation of the beam. If these effects are considered properly during design, the benefits such as longer span structure (leading to larger space) and material savings can still promote the structural application of HSS.

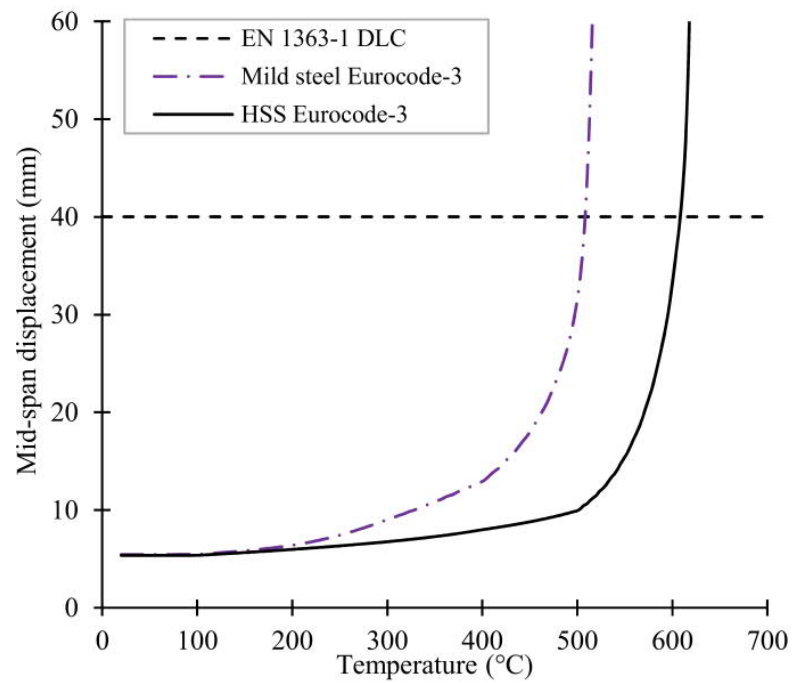

(a)

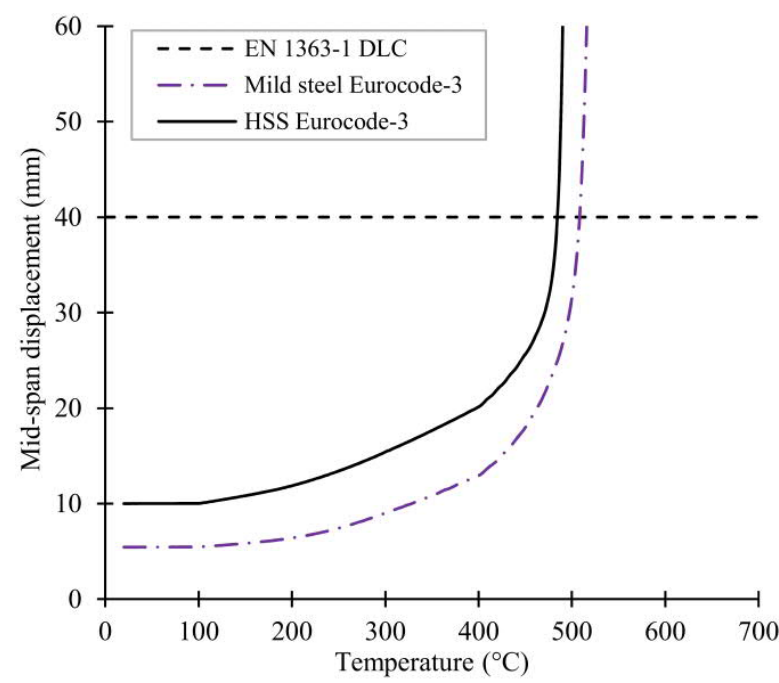

(b)

Figure 7 Mid-span deformation of mild steel $\left(\sigma_{y}=399 \mathrm{~N} / \mathrm{mm}^{2}\right)$ compared to high strength steel (S700) (a) with equal loading $\left(3 * 10^{4}\right.$ $\mathrm{kN} / \mathrm{m}^{2}$ ) and (b) with equal load ratio of 0.85. (DLC: deflection limit criterion)

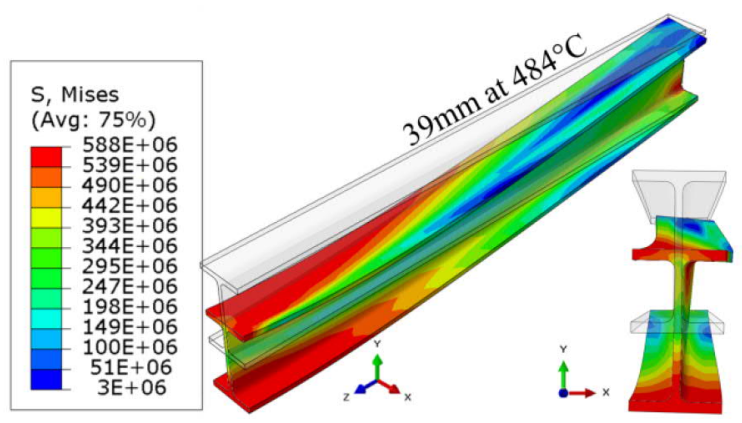

(a)

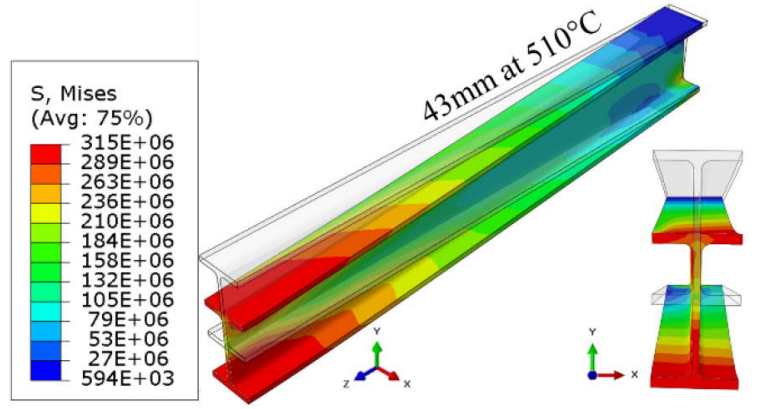

(b)

Figure 8 Stress (units $=P a$ ) contours in the half-cut section view of the beam ( 0.85 load ratio) close to 40 mm mid-span deformation (a) Eurocode-3 $S 700$ grade (b) Eurocode-3 model with $\sigma_{y}=399 \mathrm{~N} / \mathrm{mm}^{2}$

\subsection{Effects of scattering of mechanical properties on the behaviour of beam in fire}

In this section, the effects of the mechanical properties of HSS collected from literature sources on the behaviour of the beams are studied first. The effects of the deviations of these mechanical properties from the values given in EN 1993-1-2 on the behaviour of the beams are also investigated. The material models are created through the implementation of different reduction factors given for HSS in literature. Load ratio of 0.5 and 0.85 for HSS (S700) are used in the studies. Both geometrical imperfections and residual stresses are considered in FE analyses for all the cases.

For all the cases studied, Figure 9 (a) and (b) show that for the beams using the same material model the critical temperatures decreased with the increased load ratio. For the beams with load ratio of 0.5 in Figure 9 (a), uniform deformation behaviour in Stage AB is observed for all the cases. In Stage BC, the deformation of the studied beams with various material models are varied with their own temperature-dependant tangent modulus. The critical temperatures reached are varied between $601{ }^{\circ} \mathrm{C}$ and $645{ }^{\circ} \mathrm{C}$. Similarly, the trend of deformation for the beams with load ratio of 0.85 in Figure 9 (b) can be explained well with the three-stage deformation history. The critical temperatures reached are varied from $415{ }^{\circ} \mathrm{C}$ (using Qiang-model) through $448{ }^{\circ} \mathrm{C}$ (using Chiew-model and Maraveas eq1) to around $500{ }^{\circ} \mathrm{C}$ (using the 
rest of the literature material data). The deviations of both yield strength and modulus of elasticity from EN 1993-1-2 values affect the critical temperatures reached with HSS beams at different load ratios. It seems that further material tests to refine the material models provided by EN 1993-1-2 are necessary.

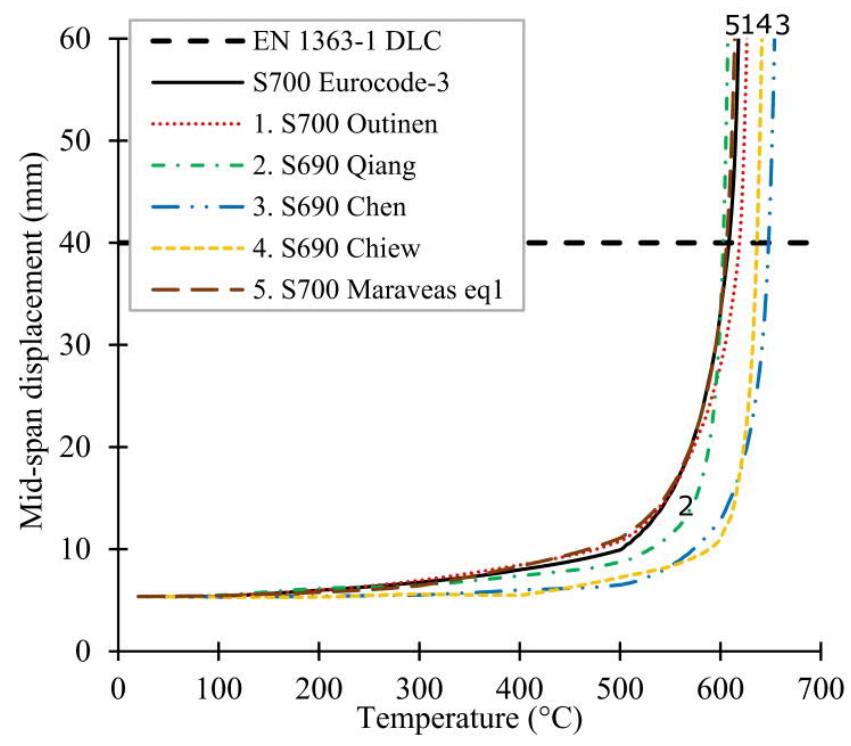

(a)

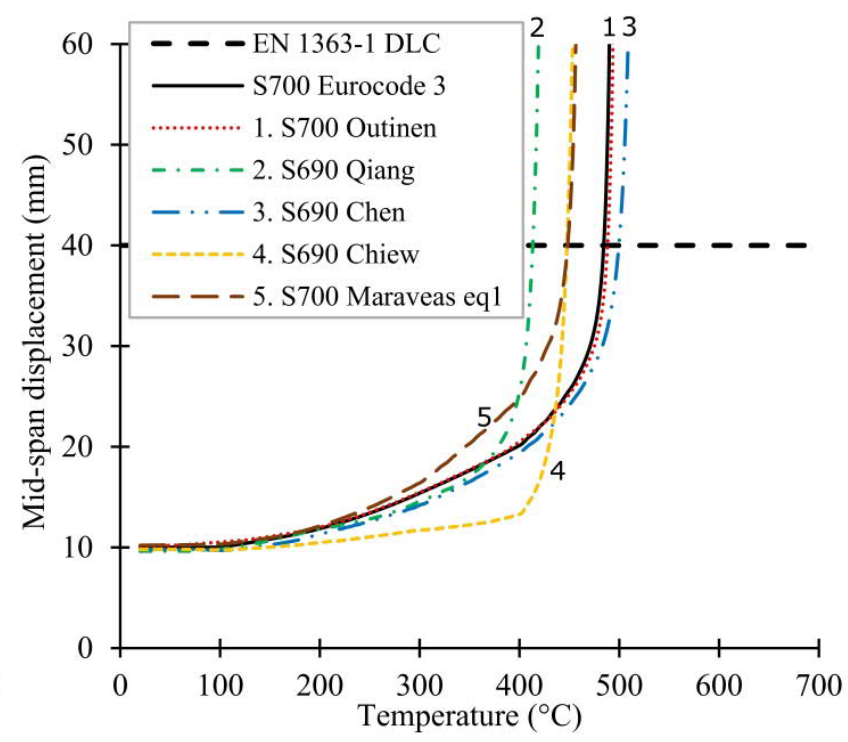

(b)

Figure 9 Mid-span deformation in HSS beam using reduction factors from different literature sources (a) Load ratio of 0.5 (b) Load ratio of 0.85. (DLC: deflection limit criterion)

\section{Behaviour of high strength steel frames at elevated temperatures}

With the understanding of the behaviour of HSS beams in fire, studies similar to the beam structure in previous section are extended to the frame structure. A two-bay frame named as ZSR1 in a series of tests conducted by Rubert and Schaumman [23] is selected for this study. The measured yield strength of $355 \mathrm{~N} / \mathrm{mm}^{2}$ is provided for both beam and column steel. The selected frame is heated in one bay only, which represents the fire compartmentation in building design. The dimensions, loads, and the support conditions are shown in Figure 10. The FE models to study the behaviour of this frame without considering the initial imperfections have been validated (by the authors of the present study) using the corresponding test results in [21]. The same validated model is used for the parametric studies in this section. Since previous studies [21] did not include imperfections and/or residual stresses, their effect on the deformation behaviour of the frame is considered in the present study.

\subsection{Validation of FE models considering geometrical imperfections and residual stresses}

A simplified residual stress distribution as depicted in Figure 3 (a) has been assigned to the individual member profiles. The initial geometric sway imperfection mode is generated by elastic buckling analysis in Abaqus. The mode shape and amplitude of imperfection is introduced in the stress analysis step through nodal displacements. The value of amplitude of imperfection for the frame is assigned according to section 5.3.2 of EN-1993-1-1 [28]. For material modelling, reduction factors and formulation equations from EN 1993-1-2 is used to produce the temperature dependent stress-strain curves for mild steel and HSS.

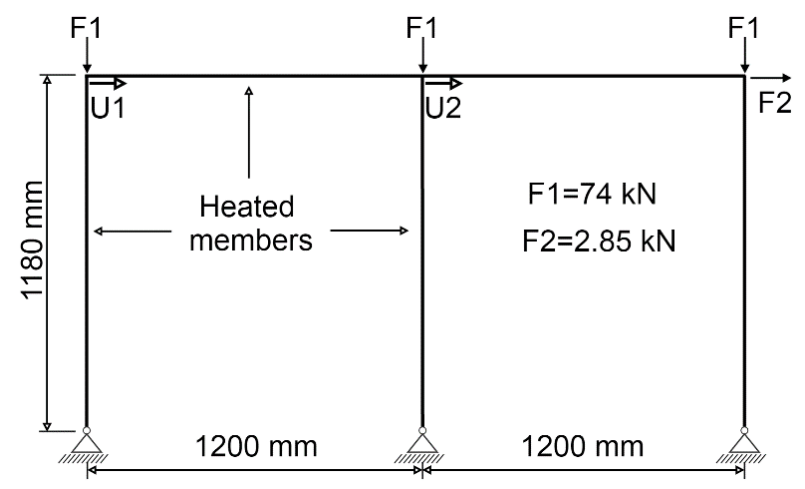

Figure 10 ZSR1 frame of IPE-80 beam profile [21] 
The effect of imperfections and residual stresses on the temperature dependent displacement behaviour of mild steel frame can be seen in Figure 11 (a). When compared to the perfect frame, the frame with the inclusion of global initial sway imperfection has an extra displacement of about $2 \mathrm{~mm}$ when the loads are applied at normal temperature. Compared to the perfect frame, overall sway deflection of the imperfect frame with respect to temperature is observed to be greater and the runaway failure occurs at lower temperature. The difference in the critical temperature is about $43{ }^{\circ} \mathrm{C}$. From Figure 11 (a) it can also be seen that compared to the inclusion of initial sway imperfection in the modelling, the residual stresses have relatively lower effect on the temperature dependent displacement behaviour of the frame. The frames with residual stresses experience slightly larger sway deflections compared to the frames without them. The presence of residual stress in steel members can substantially reduce the range of elastic behaviour, which is similar to reducing the initial value of yield strength at room temperatures. Generally, this reduction leads to slightly larger deflections in the frame in general with residual stresses.

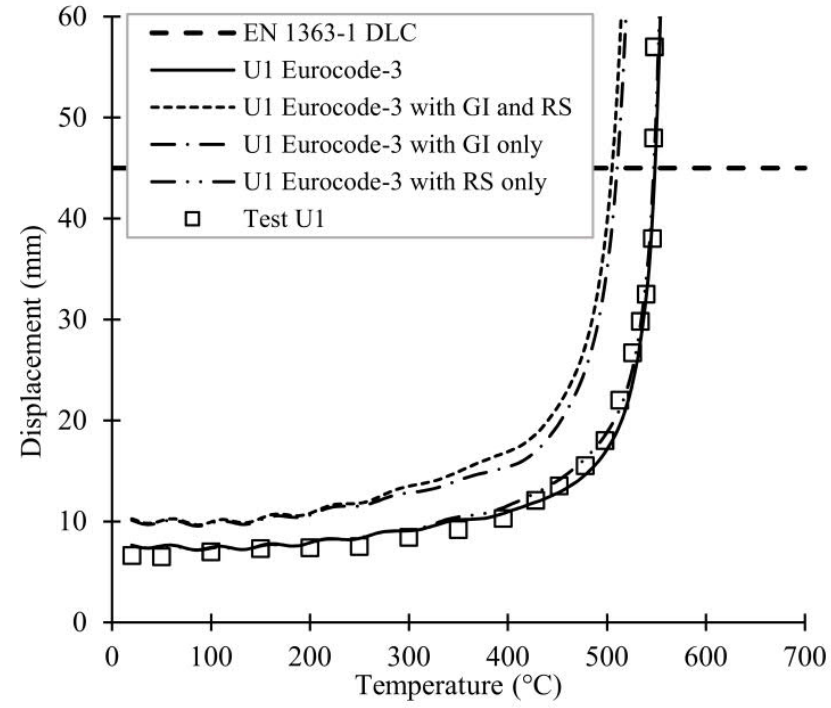

(a)

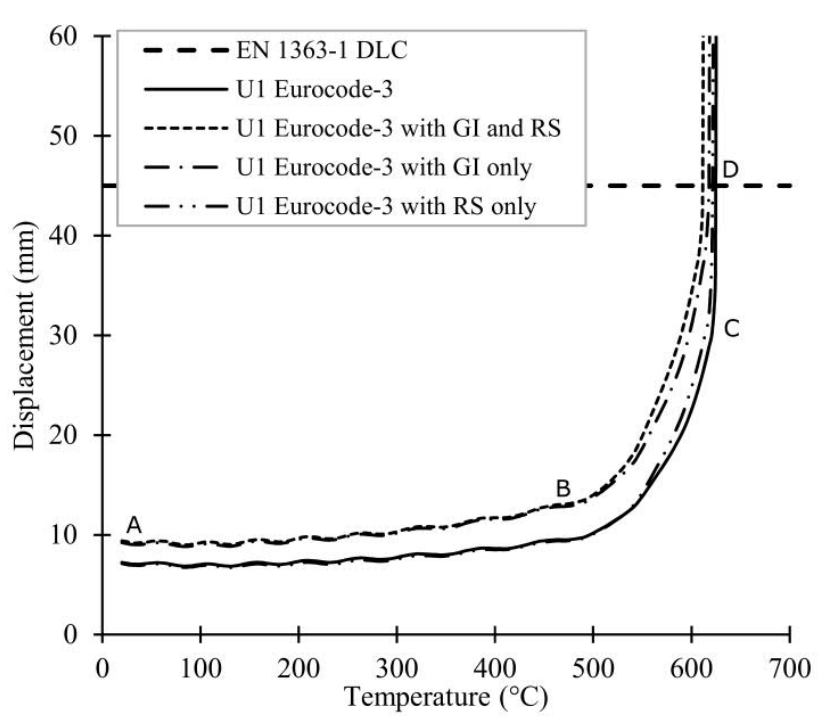

(b)

Figure 11 Horizontal displacement (of joint U1) with respect to temperature of ZSR1 frame using Eurocode-3 material data of (a)Mild steel $\left(\sigma_{y}=355 \mathrm{~N} / \mathrm{mm}^{2}\right)$ compared to test values in [23] (b) S700. (DLC: deflection limit criterion, GI: geometrical imperfection, RS: residual stress)

Figure 11 (a) also shows that the sway deflections of the frame without including geometrical imperfection coincide with the test data very well, whereas the sway deflections of the frame with geometrical imperfection do not. This may be explained by the negligible geometrical imperfections of the members in ZSR1 frames owing to their small profiles and dimensions [23].

Figure 11 (b) shows the curves of sway deflection (U1) with respect to temperature for the HSS frames with different combinations of imperfections and residual stresses. The same loads and boundary conditions as those for the mild steel frame have been used for HSS frames (Figure 11 (b)). Similar to the observations in mild steel frames, it can be seen that HSS frames with residual stresses have slightly larger deflections than the frames without them. These deflections are noticeable after $500^{\circ} \mathrm{C}$ for the frame with imperfections and after $550^{\circ} \mathrm{C}$ for the frame without imperfections. From the same figure it can be seen that the frame with initial geometrical imperfections has larger sway deflections than the perfect frame, however, these frames reach about the same critical temperatures in the end.

\subsection{Failure mechanism of the studied frame}

Figure 12 (a) to (f) show the stress contours at the corresponding critical temperatures for mild-steel and HSS frames with and without imperfections and residual stresses. In both hot bay and cold bay of the frames in Figure 12, the red colour in the legend depicts the stress levels above the yield limit at the respective temperatures of the frames. The yellow colour in the legends of the hot bay of the frames depicts the range of stress between proportional and yield limit at their respective temperatures. For the cold bay, the yellow colour of the legend starts at the true stress value corresponding to $0.2 \%$ of plastic strain. It can be seen from Figure 12 that all the frames reach their critical temperatures with certain sway deflections, and some parts of the beams undergo a certain degree of yielding. When the plastic region in the beam is large enough, its restraints to the rotations of the column tops are lost. When enough hinges are formed, the runaway failure of the frame is 
triggered by the formation of plastic hinge mechanism. Otherwise, the runaway failure of the frame is mainly triggered by its overall instability.

Figure 12 (a) shows that in the perfect mild-steel frame plastic hinges inside the beam close to the joint at the junction of cold and hot bay are developed, and partial plastic zone is observed inside the beam close to the two corner joints of the frame. It seems that the runaway failure of the perfect mild-steel frame is because of the frame instability after the formation of plastic hinge. On the other hand, no clear plastic hinges inside the beam have been observed close to the junctions of hot and cold bays for the mild steel frame with imperfections as shown in Figure 12 (b) and (c). The runaway failures of these two mild-steel frames seems to be due to frame instability. These observations on the failure mechanisms of the frames explain the deviations of the critical temperatures between the perfect frame and the frames particularly with geometrical imperfections in Figure 11. The frame with only residual stress reaches the same critical temperature as the perfect frame (Figure 11) because of the development of similar plastic hinge mechanism.

Similarly, Figure 12 (d) to (f) show that all the studied HSS frames develop clear plastic hinge inside the beam close to the junctions of the hot bay and the cold bay, and no partial plastic hinge is observed close to the right joint in the cold bay. For the frames with geometrical imperfections, no significant plastic zone has been observed in the beam close to the corner joint in hot bay. For the perfect frame, full plastic zone in the beam has been observed at the left joint of the hot bay with distortion of the profile as well. It seems that the material plastification in this region is due to axial compression. Therefore, the runaway failures of all the HSS frames are mainly due to the instability of the frame. These observations explain the relatively smaller deviations in reaching the critical temperatures for the frames with and without imperfections as shown in Figure 11 (b). 

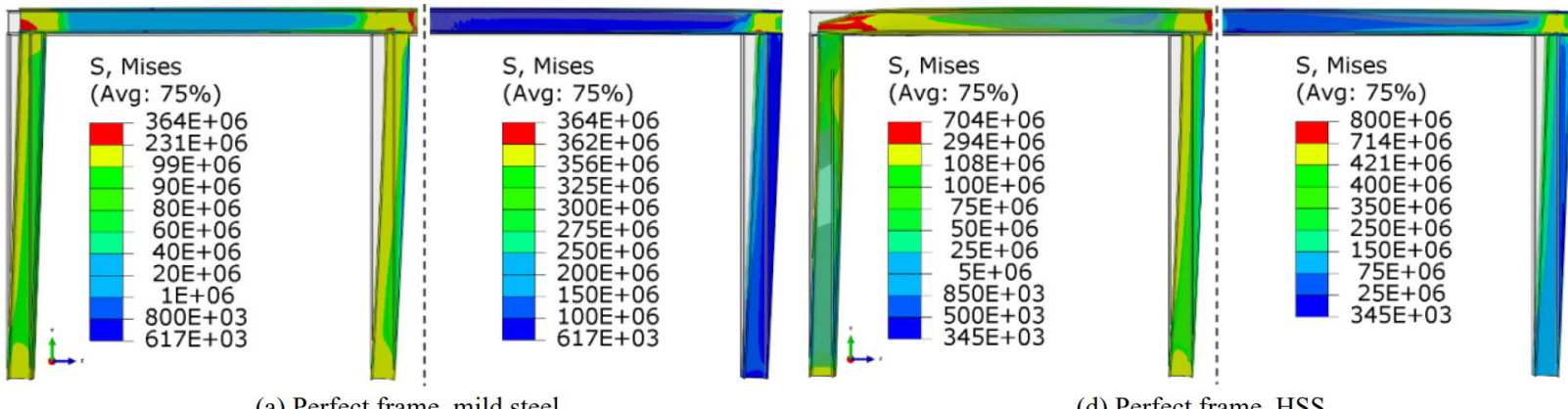

(a) Perfect frame, mild steel

(d) Perfect frame, HSS

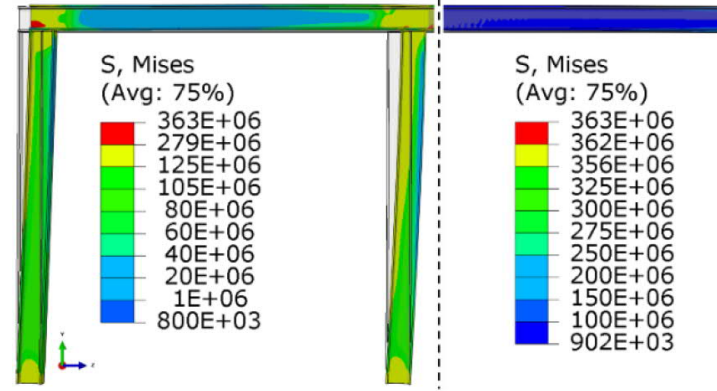

(b) Frame with geometrical imperfection, mild steel

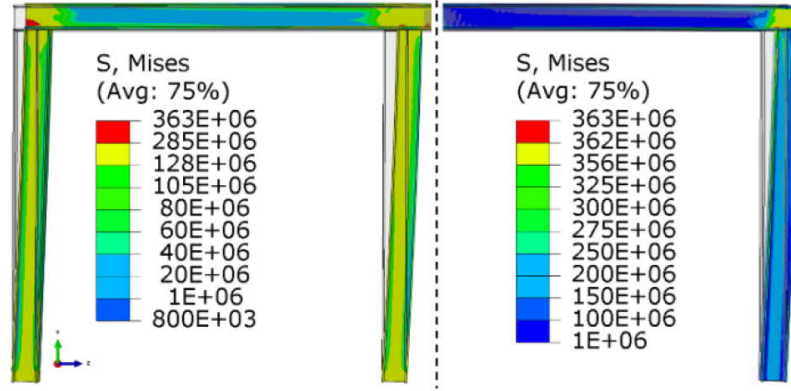

(c) Frame with geometrical imperfection and residual stress, mild steel

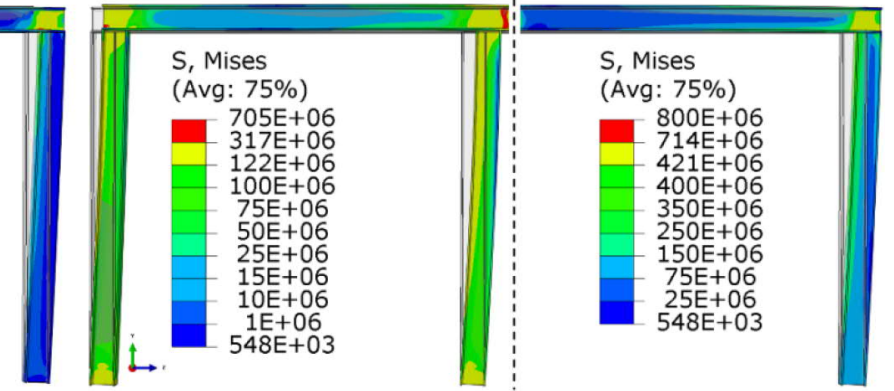

(e) Frame with geometrical imperfection, HSS

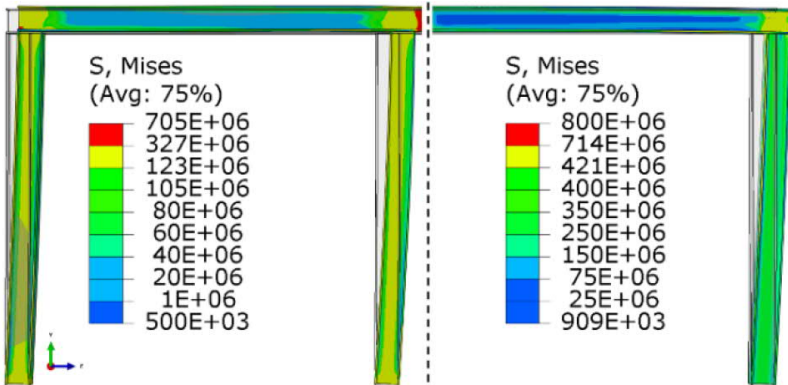

(f) Frame with geometrical imperfection and residual stress, HSS

Figure 12 Deformation mode and stress contours (units $=P a)$ at critical temperature for mild steel $\left(\sigma_{y}=355 \mathrm{~N} / \mathrm{mm}^{2}\right)$ and $\mathrm{HSS}\left(\sigma_{y}=700\right.$ $\left.\mathrm{N} / \mathrm{mm}^{2}\right)$ (a) mild steel perfect frame at U1 deflection of $40 \mathrm{~mm}\left(546{ }^{\circ} \mathrm{C}\right)$ (b) mild steel frame with geometrical imperfection at U1 deflection of $38 \mathrm{~mm}\left(503{ }^{\circ} \mathrm{C}\right)$ (c) mild steel frame with geometrical imperfection and residual stress at Ul deflection of $37 \mathrm{~mm}(497$ $\left.{ }^{\circ} \mathrm{C}\right)$ (d) HSS perfect frame at UI deflection of $36 \mathrm{~mm}\left(624^{\circ} \mathrm{C}\right)$ (e) HSS frame with geometrical imperfection at U1 deflection of $37 \mathrm{~mm}$ $\left(611^{\circ} \mathrm{C}\right)(f)$ HSS frame with geometrical imperfection and residual stress at U1 deflection of $37 \mathrm{~mm}\left(605^{\circ} \mathrm{C}\right)$

Similar to the beam, the deflection history of the perfect frame can be divided into three stages as shown in Figure 11 (b). In Stage AB, the deflection of the frame is varied linearly with temperature. The end of this stage depends on the load ratio and the exceedance of stresses corresponding to proportional limits. In Stage BC, the deflection of the frame increased rapidly with small increment of temperature. The deflection depends on the temperature dependent tangent modulus. This stage ends when the strain inside the frame due to the applied load reaches the yield strain of 0.02. In Stage CD, the plastic hinges form and the frame has large deflection. This stage ends when the deflection reaches the predefined deformation limit. The same division rule can be applied to the imperfect frame. For the determination of point $\mathrm{B}$, the limiting angle $\alpha_{\text {elastic }}=0.3^{\circ}$ is used, which coincide with the exceedance of proportional limit of stresses in the critical section of the frame. This angle is case dependent as exhaustive studies with different load combinations and thermal boundaries have not been analysed. The corresponding temperature values using the above mentioned deformation division strategy can be seen in Table 2 . 
Table 2 Maximum temperatures determined at deformation stage AB, BC, and CD of ZSR1 frame (GI: geometrical imperfection, RS: residual stress)

\begin{tabular}{|c|c|c|c|c|c|c|c|c|}
\hline Frame & \multicolumn{2}{|c|}{ Mild steel perfect } & \multicolumn{2}{|c|}{ Mild steel with GI and RS } & \multicolumn{2}{|c|}{ HSS perfect } & \multicolumn{2}{|c|}{ HSS with GI and RS } \\
\hline Temperatures & $\mathrm{FE}\left[{ }^{\circ} \mathrm{C}\right]$ & 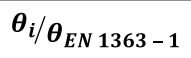 & $\mathrm{FE}\left[{ }^{\circ} \mathrm{C}\right]$ & 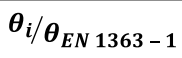 & $\mathrm{FE}\left[{ }^{\circ} \mathrm{C}\right]$ & $\theta_{i} / \theta_{E N 1363-1}$ & $\mathrm{FE}\left[{ }^{\circ} \mathrm{C}\right]$ & 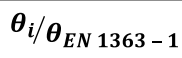 \\
\hline $\boldsymbol{\theta}_{\text {elastic }}$ & 311 & 0.56 & 212 & 0.42 & 487 & 0.75 & 369 & 0.60 \\
\hline$\theta_{L / 60}$ & 516 & 0.94 & 441 & 0.87 & 591 & 0.92 & 552 & 0.90 \\
\hline 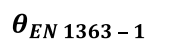 & 548 & 1 & 504 & 1 & 644 & 1 & 611 & 1 \\
\hline
\end{tabular}

As can be seen from both Figure 11 (a) and (b), the initial sway imperfections and residual stress represent the relevant conditions for studying the behaviour of these frames. The temperature-deflection curves for the frames considering both geometrical imperfections and residual stresses are used to compare the behaviour of the HSS frame to that of mild steel frame (Figure 13 (a)). The critical temperature of HSS frame is higher than that of mild steel frame by $108{ }^{\circ} \mathrm{C}$ according to $36 \mathrm{~mm}$ U1 displacement criterion (for mild steel ZSR1 frame) used in the tests by Rubert and Schaumann [23]. Runaway displacement failure is observed in both the frames close to this U1 displacement failure limit. Therefore, the use of HSS increases the load bearing capacity of ZSR1 frame and it fails at higher temperature and it takes longer time duration to fail as well. Similar trend of deformation - temperature curve and similar failure modes as of mild steel frame show that the FE model created for HSS frame is reliable and can be used for further analyses.

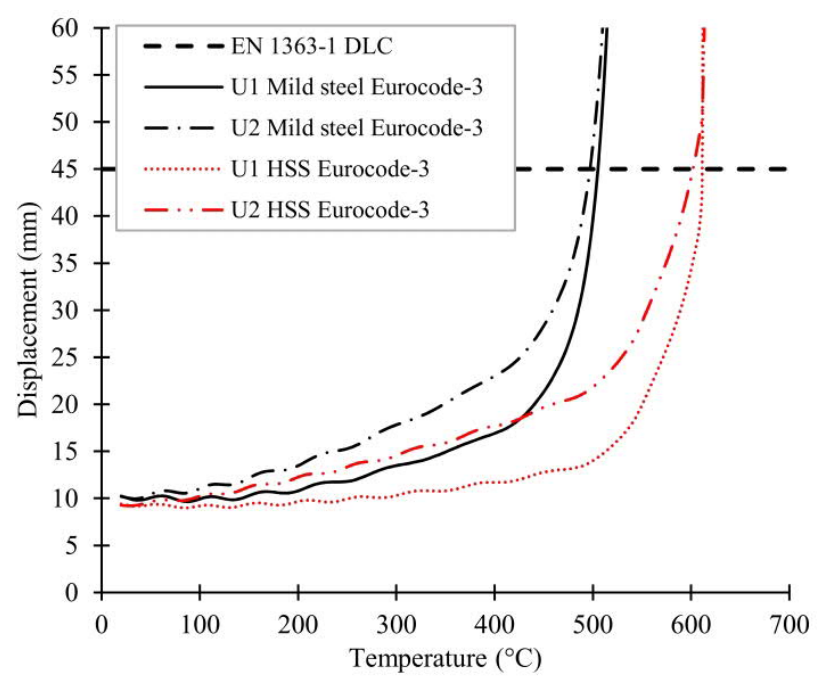

(a)

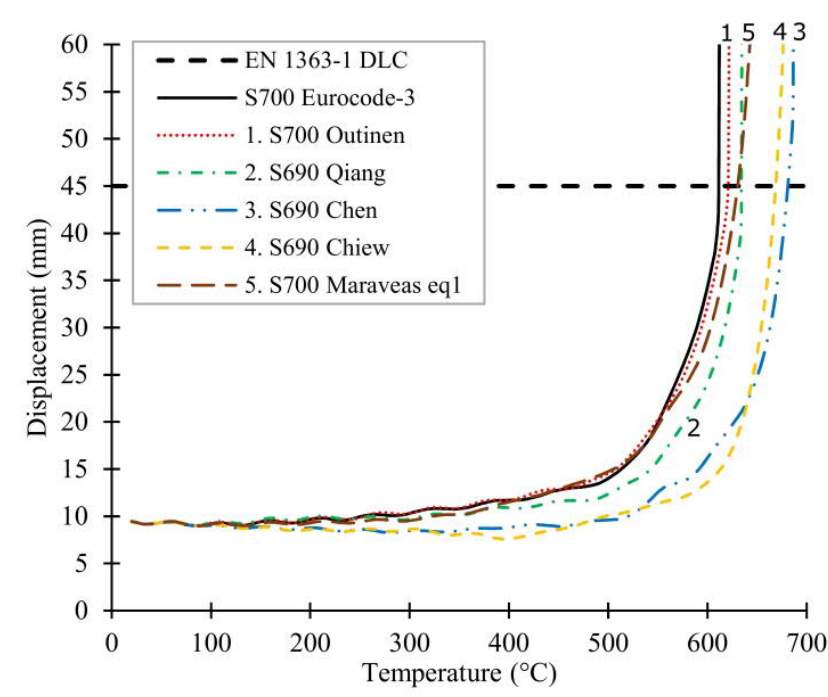

(b)

Figure 13 Horizontal displacement of ZSR1 frame (a) U1 and U2 joint using Eurocode-3 material data of HSS (S700) and mild steel $\left(\sigma_{y}=355 \mathrm{~N} / \mathrm{mm}^{2}\right)$ (b) U1 joint using literature material data of HSS (DLC: deflection limit criterion)

\subsection{Effects of scattering of mechanical properties on the behaviour of two-bay HSS frame}

The reduction factors of yield strength and modulus of elasticity provided for HSS in literature deviate from the values given in EN 1993-1-2. The material data formulated using these literature sources are used to compare their effects on the elevated temperature deformation behaviour of ZSR1 frame. Both initial sway imperfections and residual stresses are considered in the FE calculations. The results are shown in Figure 13 (b). Because of the same value of applied load, the deformation trends are consistent with the elastic modulus reduction factor trends observed in Figure 1 (b). The frame using EN 1993-1-2 reduction factors fails first at comparatively lower temperatures than the frames using literature values. The maximum difference in the critical temperature is $68{ }^{\circ} \mathrm{C}$ which is between the frames using EN 1993-1-2 and Chenmodel. The reduction factors of yield strength in Chen-model are at the same levels as those in EN 1993-1-2 but the reduction factors for modulus of elasticity in Chen-model are much higher. Therefore, the studied statically indeterminate frame is sensitive to the variations in the elastic modulus, particularly because of the inelastic instability failure. The same reason explains the observation of higher critical temperatures using Qiang-model and Chiew-model. 


\section{Effects of scattering of mechanical properties on beam and frame behaviour}

The critical temperatures of the studied beam and frame based on their respective deformation limit criterion are summarized in Table 3. The ratio of the critical temperatures using various material data model with respect to the critical temperature using EN 1993-1-2 data reveals the deviation of the critical temperatures. The critical temperature ratio is varied between 0.99 and 1.07 for the beam with load ratio of 0.5 , between 0.86 and 1.03 for the beam with load ratio of 0.85. Taking Eurocode 3 material model as the reference, Qiang-model and Chiew-model implemented in the beam structure at high load ratio underestimates the critical temperature, while the rest of the models overestimate it. Similarly, for the studied frame structure, the ratio is varied from 1.01 to 1.11. It seems that using the deformation limit criteria, both yield strength and modulus of elasticity affect the critical temperature of the structures. The runaway failure of the beam is because of the plastic hinge mechanism, therefore the scattering of the yield strength has more influence on the critical temperatures. Whereas, the runaway deformation of the frame is due to instability, therefore the scattering of the modulus of elasticity has more influence.

Table 3 Beam and frame critical temperature analysis

\begin{tabular}{|c|c|c|c|c|c|c|c|c|c|c|c|c|}
\hline \multirow{2}{*}{ Structures } & \multirow{2}{*}{ Behaviour } & \multicolumn{6}{|c|}{ Material data studied } & \multicolumn{5}{|c|}{ Comparison } \\
\hline & & $\begin{array}{c}E C 3(\text { for } \\
\text { S700) }\end{array}$ & $\begin{array}{c}\text { Outinen } \\
{[6]}\end{array}$ & $\begin{array}{c}\text { Qiang } \\
{[11]}\end{array}$ & $\begin{array}{c}\text { Chen } \\
{[10]}\end{array}$ & $\begin{array}{c}\text { Chiew } \\
{[12]}\end{array}$ & $\begin{array}{c}\text { Maraveas } \\
{[15]}\end{array}$ & $\frac{\text { outinen }}{\text { EC3 }}$ & $\frac{\text { Qiang }}{E C 3}$ & $\frac{\text { Chen }}{\text { EC3 }}$ & $\frac{\text { Chiew }}{E C 3}$ & $\frac{\text { Maraveas }}{E C 3}$ \\
\hline \multirow{2}{*}{ Beam } & $\begin{array}{c}\theta_{\text {crit }}\left({ }^{\circ} \mathrm{C}\right) \\
(L R=0.5)\end{array}$ & 605 & 618 & 601 & 645 & 637 & 608 & 1.02 & 0.99 & 1.07 & 1.05 & 1 \\
\hline & $\begin{array}{l}\theta_{\text {crit }}\left({ }^{\circ} \mathrm{C}\right) \\
(L R=0.85)\end{array}$ & 484 & 490 & 415 & 500 & 448 & 448 & 1.01 & 0.86 & 1.03 & 0.93 & 0.93 \\
\hline Frame & $\boldsymbol{\theta}_{\text {crit }}\left({ }^{\circ} \mathrm{C}\right)$ & 605 & 611 & 631 & 673 & 664 & 617 & 1.01 & 1.04 & 1.11 & 1.10 & 1.02 \\
\hline
\end{tabular}

\section{Conclusions}

The FE simulations show that similar to their mild steel peers in fire, the studied HSS structures with predefined constant load fail with uncontrolled deformation either by exceeding the capacity of material at critical sections or by losing their stability. The deformations of the studied HSS structures at elevated temperatures can be divided into three stages: linear elastic stage i.e. the stage before the material reaches the proportional limit; non-linear stage i.e. the stage before the material exceeds effective yield strength at the critical section; and yield zone propagation stage i.e. the stage before the structure fails by uncontrolled deformation. For structures with the given load, the deformation in each stage depends on the following temperature-dependent material properties: the modulus of elasticity and proportional limit, the tangent modulus and the effective yield strength, and the ratio of effective yield strength and modulus of elasticity, respectively. A limiting angle criterion to mark the start of non-linear deformation stage is introduced in order to differentiate the various stages of deformation. The proposed criterion was verified with simply supported beam and two bay frames. Further studies are required to generalize the criterion for other structures with different fire scenarios.

The three-stage deformation analysis demonstrates that HSS beams have greater strength reserve compared to mild strength beams before they have runaway failure due to plastic mechanism. Similar to the beams, the studied HSS frame exhibits higher critical temperature than the mild steel frame because of the delay in the formation of the first plastic hinge before its overall instability failure. Compared to the use of the reduction factors from literature, the use of current EN 1993-1-2 reduction factors in FE-simulation lead to under-estimation of the critical temperatures. Therefore, the strength advantage offered by the HSS was not fully utilised. The scattering of both yield strength and modulus of elasticity from literature sources affects the critical temperatures of the structures. The runaway failure of the studied beam is caused by plastic hinge mechanism, therefore, the scattering of the yield strength has more influence on the critical temperatures. Whereas, the runaway deformation of the studied frame is due to instability, therefore, the scattering of the modulus of elasticity has more influence. The behaviour of the structures depends not only on the strength but also on the integration of strength and stiffness. These observations point towards the importance of performance based design approach in fire safety design. In addition, for the future studies it is useful to take into account the thermal and the structural effects of concrete floor slab on the structural response, especially for multi-storey buildings.

\section{Acknowledgement}

The authors would like to acknowledge the Academy of Finland for supporting the current research (Project no. 289037). 


\section{References}

[1] L. Lu, G. Yuan, Z. Huang, Q. Shu and Q. Li, "Performance-based analysis of large steel truss roof structure in fire," Fire Safety Journal, vol. 93, pp. 21-38, 2017.

[2] A. Law, "The role of modelling in structural fire engineering design," Fire Safety Journal, vol. 80, pp. 89-94, 2016.

[3] X. Dai, S. Welch and A. Usmani, "A critical review of "travelling fire" scenarios for performance-based structural engineering,” Fire Safety Journal, vol. 91, pp. 568-578, 2017.

[4] EN 1993-1-2, "Design of steel structures - Part 1-2: General rules - Structural fire design,” CEN, Brussels, 2005.

[5] EN 1993-1-12, "Eurocode 3 - Design of steel structures - Part 1-12: Additional rules for the extension of EN 1993 up to steel grades S700," CEN, Brussels, 2007.

[6] J. Outinen, P. Tojakander, W. Lu and J. Puttonen, "Material Properties Of High Strength Steel In Fire," in Eurosteel 2014, Naples, 2014.

[7] W. Wang and L. Zhang, "Mechanical properties of high strength Q690 steel at elevated temperatures," in Eurosteel 2017, Copenhagen, 2017.

[8] Y. Du, J. R. Liew and M.-X. Xiong, "Effects of heat-treatment methods on mechanical performance of high-tensile strength steel subject to elevated temperatures," in Eurosteel 2017, Copenhagen, 2017.

[9] M. Neuenschwander, C. Scandella, M. Knobloch and M. Fontana, "Modeling elevated-temperature mechanical behavior of high and ultra-high strength steels in structural fire design," Materials and Design, vol. 136, pp. 81-102, 2017.

[10] J. Chen, B. Young and B. Uy, "Behavior of high strength structural steel at elevated temperatures," Journal of Structural Engineering, vol. 132, no. 12, pp. 1948-1954, 2006.

[11] X. Qiang, F. Bijlaard and H. Kolstein, "Dependence of mechanical properties of high strength steel S690 on elevated temperatures," Construction and Building Materials, vol. 30, pp. 73-79, 2012.

[12] S. Chiew, M. Zhao and C. Lee, "Mechanical properties of heat-treated high strength steel under fire / post-fire conditions," Journal of Constructional Steel Research, vol. 98, pp. 12-19, 2014.

[13] D. A. Winful, K. A. Cashell, S. Afshan, A. M. Barnes and R. J. Pargeter, "Material properties of high strength steel under fire conditions," in Eurosteel 2017, Copenhagen, 2017.

[14] EN 10025-6:2004, "Hot rolled products of structural steels - Part 6: Technical delivery conditions for flat products of high yield strength structural steels in the quenched and tempered condition," CEN, Brussels, 2009.

[15] C. Maraveas, Z. C. Fasoulakis and K. D. Tsavdaridis, "Mechanical properties of high and very high steel at elevated temperatures and after cooling down," Fire Science Reviews, vol. 6, no. 3, pp. 1-13, 2017.

[16] G.-Q. Li, L. Huang and C. Zhang, "Experimental study on high temperature elastic modulus of China made high strength structural steel," in Eurosteel 2017, Copenhagen, 2017.

[17] H. Varol and K. Cashell, "Numerical modelling of high strength steel beams at elevated temperature," Fire Safety Journal, vol. 89, pp. 41-50, 2017.

[18] X. Qiang, F. S. Biljaard, H. Kolstein and X. Jiang, "Behaviour of beam-to-column high strength steel end plate connections under fire conditions - Part 2: Numerical study," Engineering Structures, vol. 64, pp. 39-51, 2014.

[19] J. Chen and B. Young, "Design of high strength steel columns at elevated temperatures," Journal of constructional steel research, vol. 64, no. 6, pp. 689-703, 2008. 
[20] D. A. Winful, S. Afshan, K. A. Cashell, A. M. Barnes and R. J. Pargeter, "Flexural buckling behaviour of high strength steel columns under fire conditions," in Eurosteel 2017, Copenhagen, 2017.

[21] S. Shakil, W. Lu and J. Puttonen, "Behaviour of plane frames of high strength steel in fire," in Eurosteel 2017, Copenhagen, 2017.

[22] Abaqus 6.13 Analysis user guide, Providence, RI, USA: Dassault Systèmes, 2013.

[23] A. Rubert and P. Schaumann, "Structural steel and plane frame assemblies under fire action," Fire Safety Journal, vol. 10, pp. 173-184, 1986.

[24] B. A. Izuddin, L. Song, A. S. Elnashai and P. J. Dowling, "An integrated adaptive environment for fire and explosion analysis of steel frames - Part II: verification and application," Journal of Constructional Steel Research, vol. 53, no. 1, pp. 87-111, 2000.

[25] H. M. Ali, P. E. Senseny and R. L. Alpert, "Lateral displacement and collapse of single-story steel frames in uncontrolled fires,” Engineering Structures, vol. 26, no. 5, pp. 593-607, 2004.

[26] B. Jiang, G.-Q. Li and A. Usmani, "Progressive collapse mechanisms investigation of planar steel moment frames under localized fire," Journal of Constructional Steel Research, vol. 115, pp. 160-168, 2015.

[27] R. Sun, Z. Huang and I. W. Burgess, "Progressive collapse analysis of steel structures under fire conditions," Engineering Structures, vol. 34, pp. 400-413, 2012.

[28] EN 1993-1-1, “Design of steel structures - Part 1-1: General rules and rules for buildings,” CEN, Brussels, 2005.

[29] EN 1363-1, "Fire resistance tests - Part 1: General requirements,” CEN, Brussels, 2012. 